\title{
A new leveling method without the direct use of crossover data and its application in marine magnetic surveys: weighted spatial averaging and temporal filtering
}

\author{
Takemi Ishihara
}

\begin{abstract}
The author has developed a new leveling method for use with magnetic survey data, which consists of adjusting each measurement using the weighted spatial average of its neighboring data and subsequent temporal filtering. There are two key parameters in the method: the 'weight distance' represents the characteristic distance of the weight function and the 'filtering width' represents the full width of the Gaussian filtering function on the time series. This new method was applied to three examples of actual marine survey data. Leveling using optimum values of these two parameters for each example was found to significantly reduce the standard deviations of crossover differences by one third to one fifth of the values before leveling. The obtained time series of correction values for each example had a good correlation with the magnetic observatory data obtained relatively close to the survey areas, thus validating this new leveling method.
\end{abstract}

Keywords: Leveling method; Crossover difference; Weighted average; Gaussian filter; Magnetic anomaly; Marine magnetic survey; Temporal variation

\section{Background}

The magnetic field at the Earth's surface is mainly composed of three contributions with different origins: core-derived main field, temporal variation relating to ionospheric and magnetospheric sources, and an anomaly due to lithospheric sources (e.g., Sabaka et al. 2002). Lithospheric magnetic data being collected using the state-of-theart Swarm magnetic field mission launched in November 2013 (Olsen et al. 2013) will still have limitations related to spatial wavelengths, i.e., shorter wavelength components can only be revealed by near-surface surveys. Unlike deep-sea measurements with magnetometers fixed to autonomous underwater vehicles (AUVs), remotely operated vehicles (ROVs), or submersibles, or measurements on-board surface ships, in which the corrections of magnetic fields produced by the vehicles are essential for obtaining accurate

Correspondence: t-ishihara@aist.go.jp

Institute of Geology and Geoinformation, Geological Survey of Japan,

National Institute of Advanced Industrial Science and Technology, Central 7, 1-1-3 Higashi, Tsukuba, Ibaraki 305-8567, Japan anomaly data (e.g., Isezaki 1986; Honsho et al. 2013; Szitkar et al. 2014), in recent marine surveys by surface ships with the magnetometer sensors towed using cables long enough to avoid the ship magnetic effect, measurement errors (including errors in Global Positioning System (GPS) navigation) are usually less than these three contributions (e.g., Hamoudi et al. 2011). The accuracy of the measured magnetic anomaly depends on how well it can be separated from the other components. The main field and its secular variation can be modeled well by the International Geomagnetic Reference Field (IGRF) (International Association of Geomagnetism and Aeronomy Working Group V-MOD 2010), Comprehensive Model 4 (CM4) (Sabaka et al. 2004), or other reference field models, and therefore, the temporal variation due to external origins is the main source of error in marine magnetic surveys by surface ships with towed magnetometer sensors.

\section{勿}

(c) 2015 Ishihara; licensee Springer. This is an Open Access article distributed under the terms of the Creative Commons Attribution License (http://creativecommons.org/licenses/by/4.0), which permits unrestricted use, distribution, and reproduction in any medium, provided the original work is properly credited. 
It is possible to correct temporal variation using measurements at a base station or at a neighboring observatory, but it is not always possible to establish a base station or locate an observatory close enough to the survey area. Therefore, if a model of ionospheric and magnetospheric currents (such as CM4) cannot be used, leveling methods are required to reduce the effect of temporal variation. Crossover differences (CODs) are calculated in most leveling methods, and a correction in temporal variation is carried out to reduce the differences by assuming that the variation is a linear, polynomial, or sinusoidal function of time (Yarger et al. 1978; Sander and Mrazek 1982; Mittal 1984; Hsu 1995; Wessel 2010). Here, the author has developed a new leveling method, which consists of the calculation of corrections obtained by adjusting each measurement to a weighted average of its neighboring data, and a time-domain filtering calculation of these corrections. Although the CODs themselves are not utilized in this method, they can be reduced by giving the largest weights to the nearest neighboring data. In Quesnel et al. (2009), a preliminary version of this method was applied to a CM4-corrected global marine magnetic anomaly data set, and this reduced the root mean square (RMS) COD from 78.4 to $47.7 \mathrm{nT}$. However, a detailed description of the method was not given.

This paper first describes the method used and then presents three examples using data from observatories located relatively close to the survey areas. In order to simplify the explanation, each of these examples uses survey data from one or two cruises that occurred within the same time periods (within a few months), so that the effects of the secular variation in the main field can be neglected. In order to evaluate the effectiveness of the method, the obtained leveling corrections are then compared with the results from the nearest observatory data, and the effects of the parameters used in the method are also discussed.

\section{Methods}

The basic premise of the new leveling method is that each correction is calculated to minimize the difference between the measurement and its expected value determined by its neighboring data, yet the correction should be a slowly varying function of time. For the expected value of a measurement, a weighted average of its neighboring data is considered, and the weight of a neighboring point is determined as a rapidly decreasing function of its distance from the measured point (Figure 1). If each measurement is adjusted to its expected value, the COD will decrease because the weight of the nearest point becomes the largest amongst all the neighboring data. If the original value of the $i$-th measurement and its correction are expressed as $a_{i}$ and $c_{i}$, respectively, the corrected value

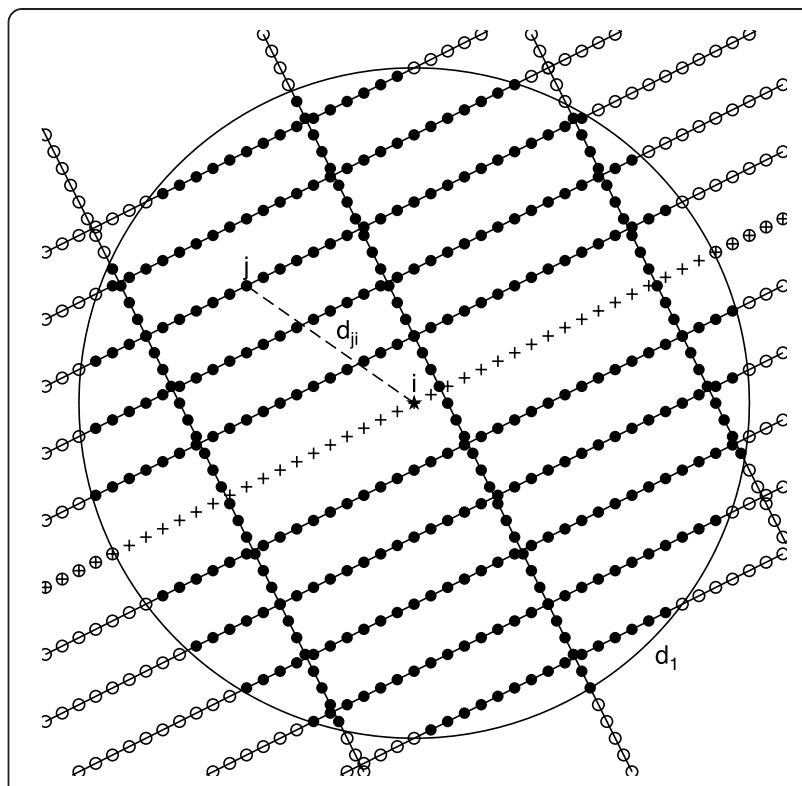

Figure $1 \mathrm{~A}$ measurement and its expected value. The expected value of the $i$-th measurement is obtained using a weighted average of all the data (filled circles) within the circle, with the center at the $i$-th data point and a radius of $d_{1}$. The data outside of this circle (open circle) are not included in the weighted average. However, the $i$-th measurement itself and its nearest data in time (plus marks) should be excluded from this average. The weight of the $j$-th measurement is a rapidly decreasing function of its distance from the $i$-th measurement $d_{j j}$.

can be expressed as the weighted average of its neighboring data as follows:

$$
a_{i}+c_{i}=\sum_{j} T\left(t_{j}-t_{i}\right) W\left(d_{j i}\right)\left(a_{j}+c_{j}\right) / \sum_{j} T\left(t_{j}-t_{i}\right) W\left(d_{j i}\right)
$$

This equation can be transformed to:

$$
c_{i}=\delta_{i}
$$

where:

$$
\delta_{i} \equiv \sum_{j} T\left(t_{j}-t_{i}\right) W\left(d_{j i}\right)\left(c_{j}+a_{j}-a_{i}\right) / \sum_{j} T\left(t_{j}-t_{i}\right) W\left(d_{j i}\right)
$$

Here, $t_{i}$ and $t_{j}$ denote times of the $i$-th and $j$-th measurements, respectively, and $d_{j i}$ denotes the distance between both measurements. $\sum_{j}$ represents the summation on $j$. The function $T(t)$ is introduced to exclude the contribution from the $i$-th measurement itself and its nearest data in time, which are considered to vary in a manner similar to the measurement (the explicit form of the function $T(t)$ will be described later).

In order to rapidly reduce contributions from relatively distant measurements, a weight function $W(d)$ is adopted, 
which decreases approximately as a negative fourth power of their distances according to:

$$
\begin{aligned}
& W(d)=1 /\left[1+\left(d / d_{0}\right)^{2}\right]^{2} \text { if } d<d_{1} \\
& \text { and }=0 \quad \text { if } d>d_{1}
\end{aligned}
$$

The parameter $d_{0}$ is a characteristic distance, which the author refers to as a 'weight distance.' This function decreases slowly from 1 (at $d=0$ ) to one fourth (at $d=d_{0}$ ), but it decreases more rapidly when $d>d_{0}$ and takes a value of $1 / 25$ at $d=2 d_{0}$ (Figure 2). The parameter $d_{1}$ defines the distance limit of this weight function. A value of $15 \mathrm{~km}$ is adopted as the distance limit $d_{1}$, and therefore the summation $\sum_{j}$ is only carried out for data obtained inside $15 \mathrm{~km}$ from the $i$-th point.

A simple form of function $T(t)$ is selected (Figure 3A) as follows:

$$
\begin{aligned}
T(t) & =1 & \text { if } & |t|>2 t_{1} \\
& =|t| / t_{1}-1 & \text { if } & t_{1}<|t|<2 t_{1} \\
\text { and } & =0 & \text { if } & |t|<t_{1}
\end{aligned}
$$

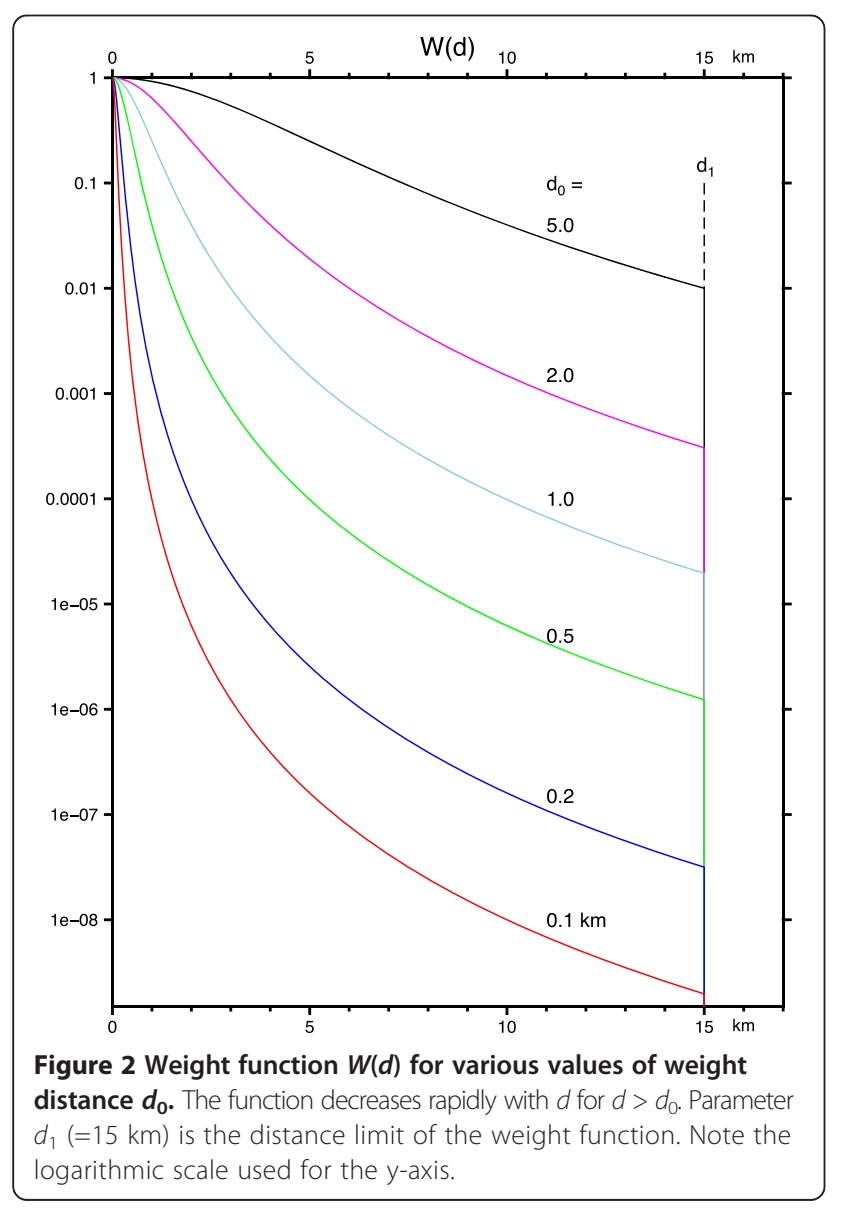

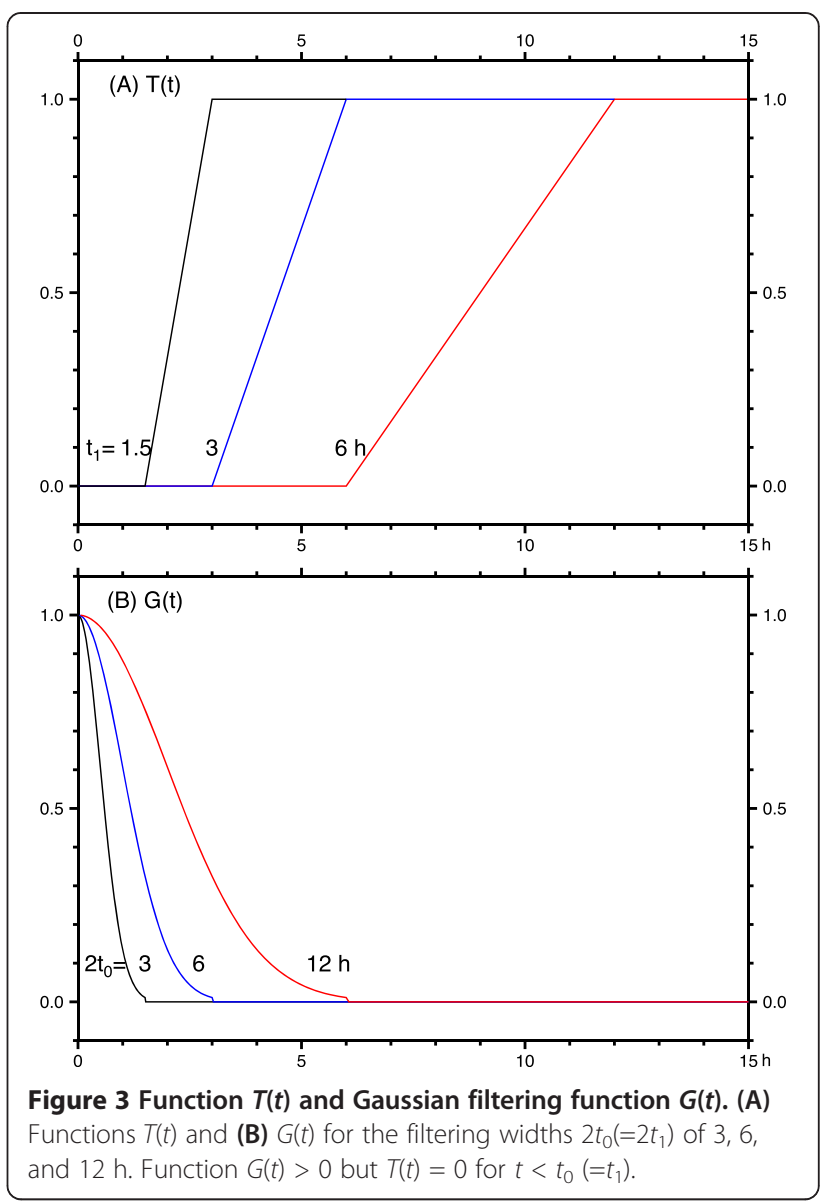

The correction $c_{i}$ obtained by Equations 2 and 3 can vary rapidly in time. In order to reduce such rapid variation, weighted low-pass filtering is introduced as follows:

$$
c_{i}=\sum_{k} \delta_{k} G\left(t_{k}-t_{i}\right) \gamma_{k} / \sum_{k} G\left(t_{k}-t_{i}\right) \gamma_{k}
$$

Here, $G(t)$ is a filtering function and $\gamma_{k}$ is the weight of the $k$-th measurement. A Gaussian filter with a full width of $2 t_{0}$ (referred to as the 'filtering width' in this paper) is adopted as the filtering function (Figure 3B):

$$
\begin{aligned}
& G(t)=\exp \left[-4.5\left(t / t_{0}\right)^{2}\right] \quad \text { if }|t|<t_{0} \\
& \text { and }=0 \quad \text { if }|t|>t_{0}
\end{aligned}
$$

Although the parameters $t_{0}$ and $t_{1}$ can be different, they are assumed to be equal, and the filtering of corrections is calculated without contribution from the data themselves.

The filtering weight of the $i$-th measured point, $\gamma_{i}$, will be greater if there are more neighboring data around it. Thus, the denominator on the right hand side of Equation 3 
is assumed as the filtering weight $\gamma_{i}$. Equation 6 thus becomes:

$$
\begin{aligned}
& c_{i}=\left(\beta_{1 i}+\beta_{2 i}\right) / f_{i} \\
& \beta_{1 i} \equiv \sum_{k} G\left(t_{k}-t_{i}\right) \sum_{j} T\left(t_{j}-t_{k}\right) W\left(d_{j k}\right) c_{j} / \sum_{k} G\left(t_{k}-t_{i}\right) \\
& \beta_{2 i} \equiv \sum_{k} G\left(t_{k}-t_{i}\right) \sum_{j} T\left(t_{j}-t_{k}\right) W\left(d_{j k}\right)\left(a_{j}-a_{k}\right) / \sum_{k} G\left(t_{k}-t_{i}\right) \\
& \text { and } f_{i} \equiv \sum_{k} G\left(t_{k}-t_{i}\right) \sum_{j} T\left(t_{j}-t_{k}\right) W\left(d_{j k}\right) / \sum_{k} G\left(t_{k}-t_{i}\right)
\end{aligned}
$$

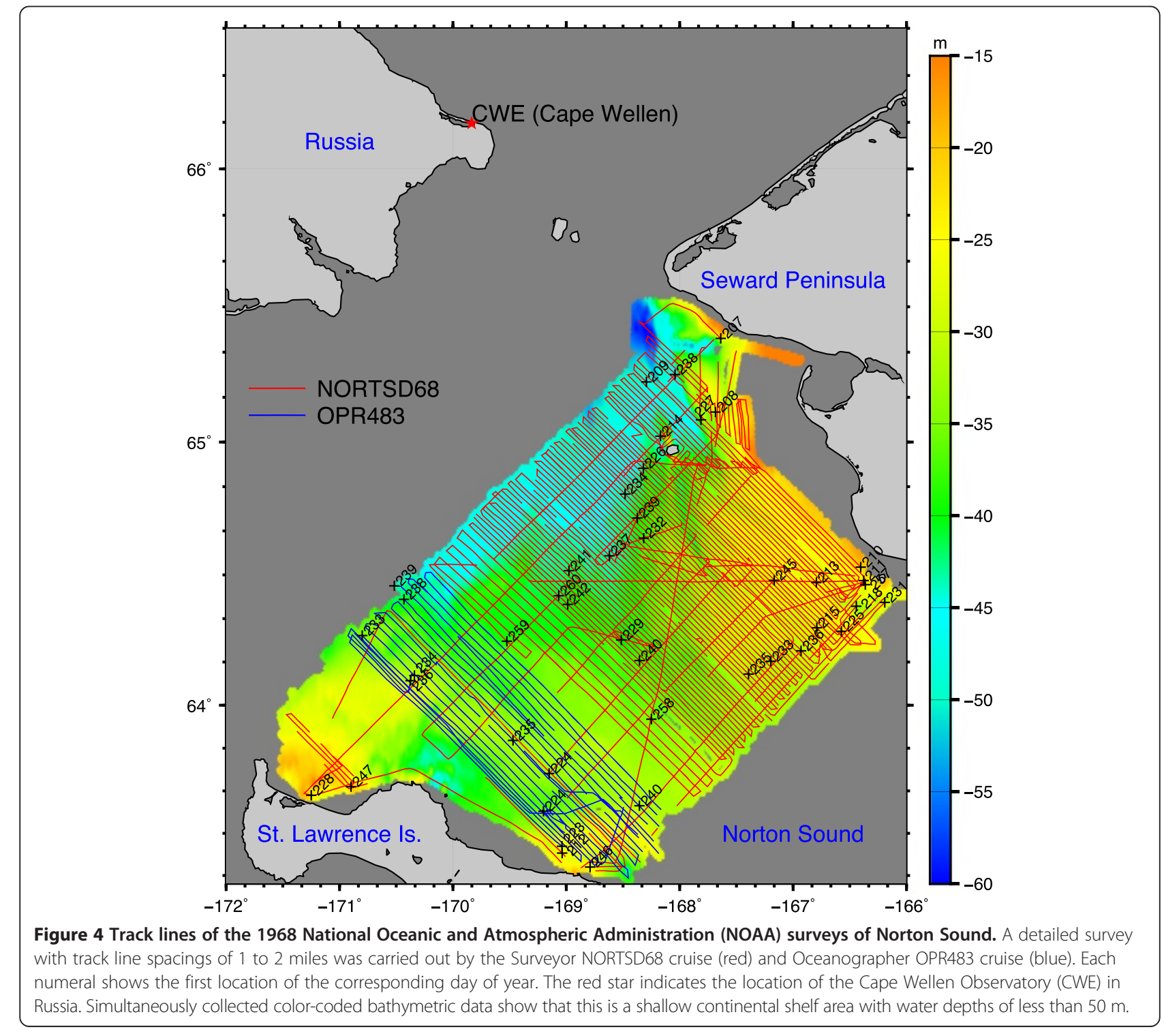

Figure 4 Track lines of the 1968 National Oceanic and Atmospheric Administration (NOAA) surveys of Norton Sound. A detailed survey with track line spacings of 1 to 2 miles was carried out by the Surveyor NORTSD68 cruise (red) and Oceanographer OPR483 cruise (blue). Each numeral shows the first location of the corresponding day of year. The red star indicates the location of the Cape Wellen Observatory (CWE) in Russia. Simultaneously collected color-coded bathymetric data show that this is a shallow continental shelf area with water depths of less than 50 m.
The term $\beta_{1 i}$ includes only an unknown $c_{j}$, while $\beta_{2 i}$ includes only the original values $a_{j}$ and $a_{k}$.

Formula 8 can be used only in a case where the sum of the filtering weights $f_{i}$ is large enough. In order to avoid instability of the solution, the author made corrections smaller for cases of smaller $f_{i}$. The revised formula is as follows:

$$
\begin{aligned}
& \begin{aligned}
c_{i} & =\beta_{1 i} / f_{i}+\beta_{2 i} / f_{i} \quad \text { if } f_{i}>f_{1} \\
& =\beta_{1 i} / f_{1}+\beta_{2 i} / f_{1} \quad \text { if } \quad f_{2}<f_{i}<f_{1} \\
& =\beta_{1 i} f_{i} /\left(f_{1} f_{2}\right)+\beta_{2 i} f_{i} /\left(f_{1} f_{2}\right) \quad \text { if } \quad 0<f_{i}<f_{2}
\end{aligned} \\
& \text { and }=0 \quad \text { if } \quad f_{i}=0
\end{aligned}
$$


where $f_{1}$ and $f_{2}$ are appropriate constants (in the following three examples, reasonable results were obtained by assigning 0.2 and 0.05 to the values of $f_{1}$ and $f_{2}$, respectively), and $\beta_{1 i}, \beta_{2 i}$, and $f_{i}$ are calculated by Equations $9 \mathrm{a}, 9 \mathrm{~b}$, and 10 , respectively.

It is worth noting that if one solution is available for Equation 8 or 11a, another solution can be obtained using all the corrections added with an arbitrary constant. However, $c_{i}$ should be close to 0 in general, and a reasonable solution of $c_{i}$ can be obtained by iteration of these equations with the initial value of 0 on the right hand side of Equations 11a to 11c. In order to obtain the $n+1$-th estimate of this iteration calculation, the data set is divided into time order groups of positive and negative values of $\delta c_{i}^{(n)}$, where $\delta c_{i}^{(n)}=c_{i}^{t}-c_{i}^{(n)}$ and $c_{i}^{t}$ are obtained by putting the $n$-th estimate $c_{i}^{(n)}$ into the right hand side

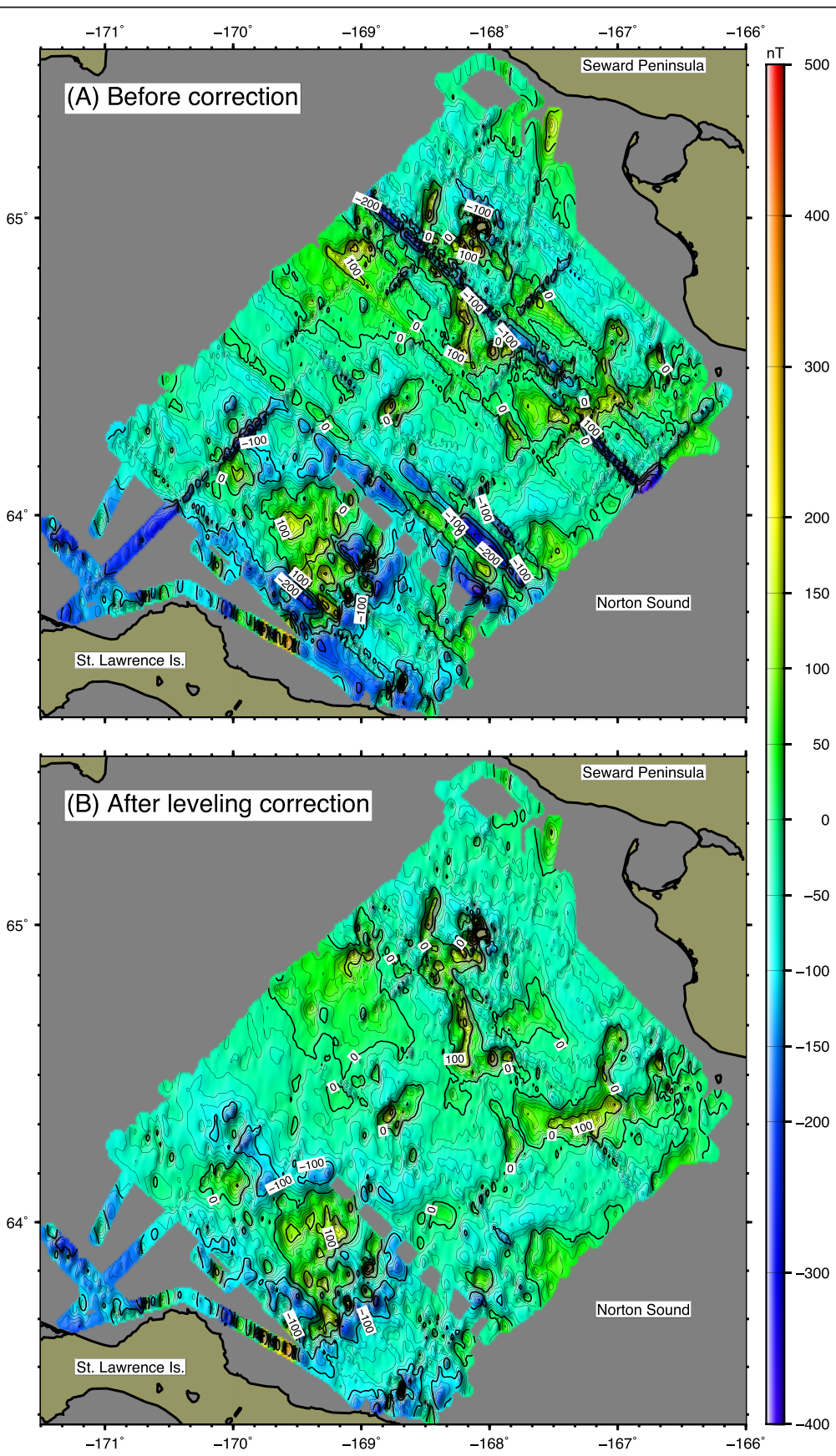

Figure 5 Magnetic anomaly maps of Norton Sound before and after leveling correction. Prominent false-lineated anomalies along the track lines in the map before correction (A) almost disappear after leveling correction using a filtering width of $3 \mathrm{~h}$ and a weight distance of $2 \mathrm{~km}$ (B). Contours are at $20 \mathrm{nT}$ intervals; thicker contours are at $100 \mathrm{nT}$ intervals. 


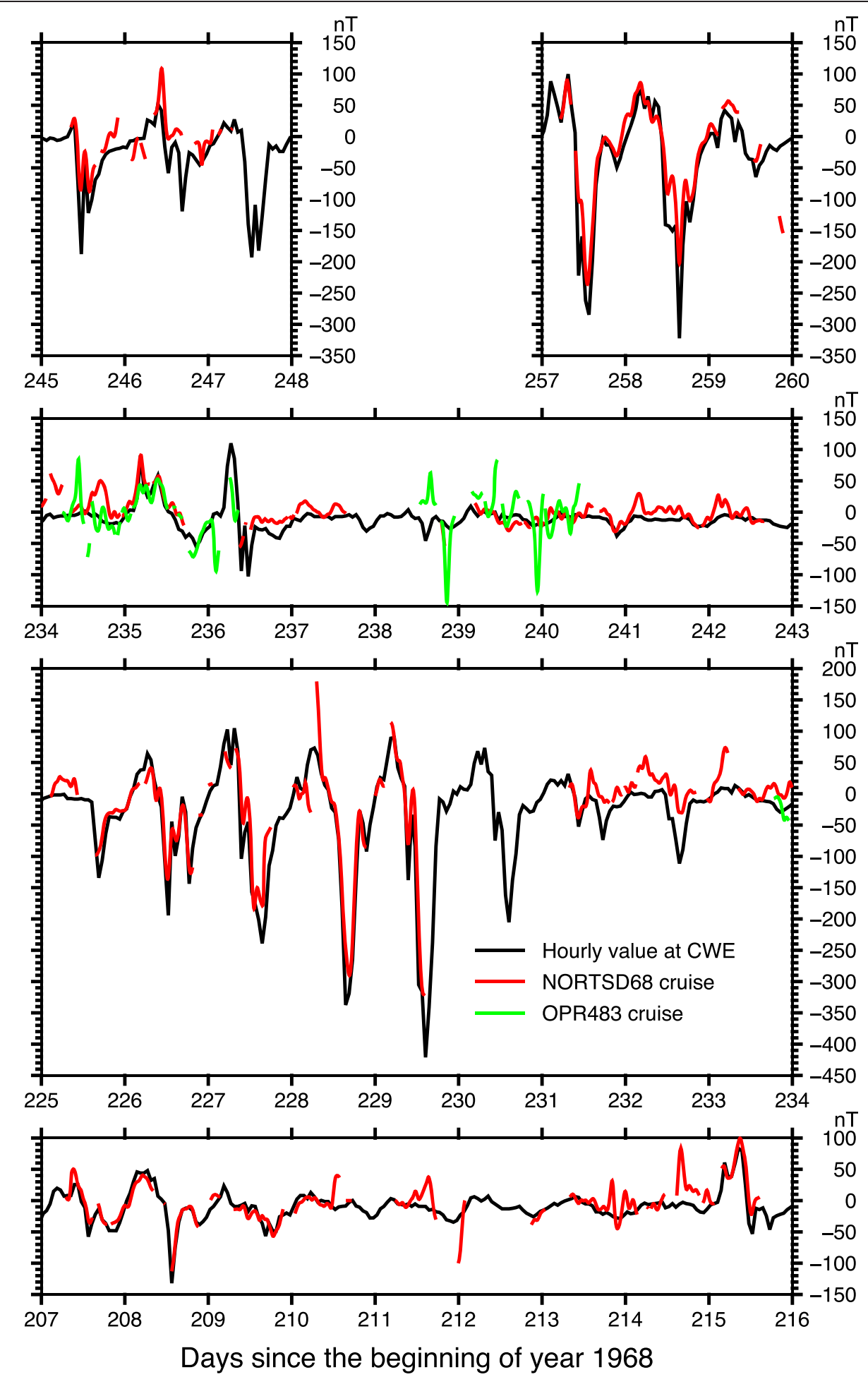

Figure 6 Comparison of the total magnetic intensity hourly values at the Cape Wellen Observatory (CWE) and leveling corrections. Variations of leveling corrections along the track lines of the NORTSD68 (red) and OPR483 (green) cruises closely follow the hourly values (black). An approximate value of 55,400 nT is subtracted from the hourly values. The location of the CWE is shown in Figure 4. 
of Equations 11a to 11c. The $n+1$-th estimate of the data set is created by replacing only $c_{i}^{(n)}$ in the group, which includes the maximum of $\left|\delta c_{i}^{(n)}\right|$, by $c_{i}^{t}$. The calculation is iterated until the maximum of $\left|\delta c_{i}^{(n)}\right|$ becomes smaller than a predetermined threshold value. This is a method that ensures convergence, although it requires many iterations. After convergence of the iteration, the corrected value $b_{i}$ can be calculated using equation $b_{i}=a_{i}+c_{i}$.

\section{Results}

\section{Example 1: Norton Sound survey}

In 1968, Norton Sound of Alaska was surveyed using two National Oceanic and Atmospheric Administration (NOAA) vessels during the Surveyor NORTSD68 cruise and Oceanographer OPR483 cruise (Figure 4). The author found data of microfilm image listings with sampling periods of $1 \mathrm{~min}$ or shorter (available as Geophysical Data System (GEODAS) analog data from the US National Geophysical Data Center). According to reports found in the same microfilm images, Loran- $\mathrm{C}$ and transit satellite navigation were mainly used during the Oceanographer survey resulting in a possible positional accuracy of about $1 \mathrm{~km}$, while the Surveyor cruise was carried out using the more accurate medium-frequency radio navigation system Raydist. The author created digital data at 5-min intervals by reading navigational, magnetic, and bathymetric data listings. This is a shallow continental shelf area, where short wavelength magnetic anomalies could exist (Figure 4).

Magnetic anomalies were calculated using the CM4 main field model with orders up to 15 (Sabaka et al. 2004). However, the anomaly map made from the calculated data showed very prominent, mostly negative, false-lineated anomalies along the track lines (Figure 5A). These were considered to be probably due to largeamplitude time variations near the auroral zone. A good result was then obtained by applying the method described above to this data set using a filtering width of $3 \mathrm{~h}$ and a weight distance of $2 \mathrm{~km}$ (Figure 5B). Results show that most of the false anomalies along the track lines almost disappeared, and anomalies associated with geologic sources were clearly identified in the anomaly map made using the corrected data.

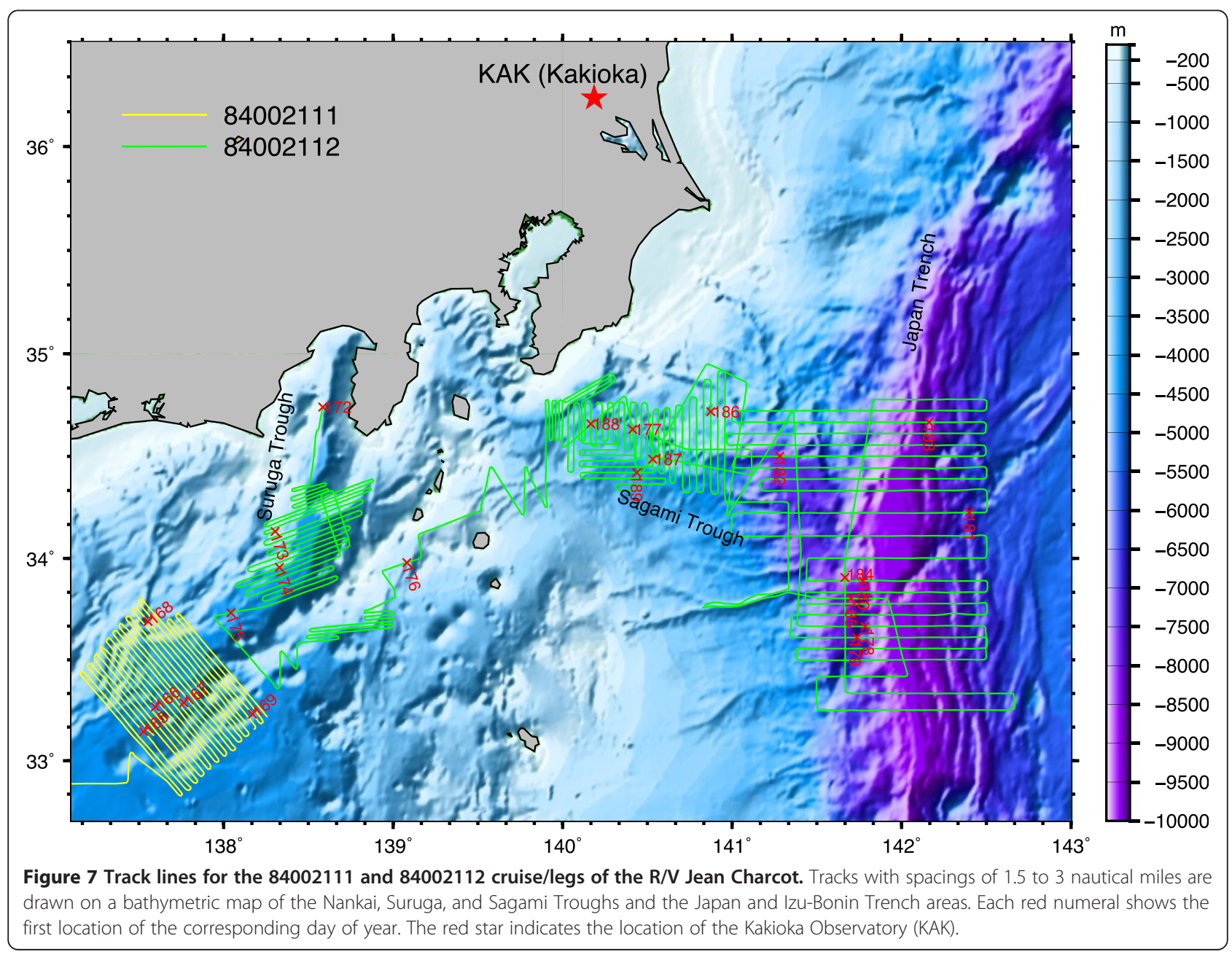


There is a high correlation between the corrections of anomalies along the track lines and the hourly total intensity values recorded at the Cape Wellen Observatory (CWE) in Russia (location shown in Figure 4), which is the nearest observatory to the survey area in the Geomagnetic Data Master Catalog at the World Data Center for Geomagnetism (Figure 6). As described before, the navigation quality of the OPR483 cruise is poorer than that of the NORTSD68 cruise. There were a few spikes in the leveling corrections with an amplitude of about 100 to $150 \mathrm{nT}$ in the former cruise data (green curve), but no corresponding variations were recognized in the hourly values at CWE. The author suspects that these discrepancies were caused by navigational errors. He also suspects that the navigational errors in the former cruise resulted in a large discrepancy of more than 100 nT on day 228 of the latter cruise (red curve), because such data were obtained at about $\left(63.4^{\circ} \mathrm{N}, 168.8^{\circ} \mathrm{W}\right)$ in the area with many tracks from the OPR483 cruise. The data from the observatory occasionally shows large amplitude variations, with amplitudes of up to $400 \mathrm{nT}$. Apart from the discrepancies described above, most of the calculated corrections along the survey track lines closely followed the variations at CWE. This suggests that the actual time variation due to external sources was sufficiently corrected for using the proposed method. The standard deviation of 1,021 CODs was reduced to $1 / 2.7$ (from 74.6 to $28.0 \mathrm{nT}$ ) by use of this method.

\section{Example 2: Kaiko project}

In 1984, subduction areas near the Japanese Islands were surveyed using the French research vessel Jean Charcot (Figure 7; Le Pichon et al. 1987). A combination of Loran-C, transit satellite, and GPS navigation equipment were used with an estimated accuracy of 50 to $100 \mathrm{~m}$. Digital magnetic data at 1-min intervals are available
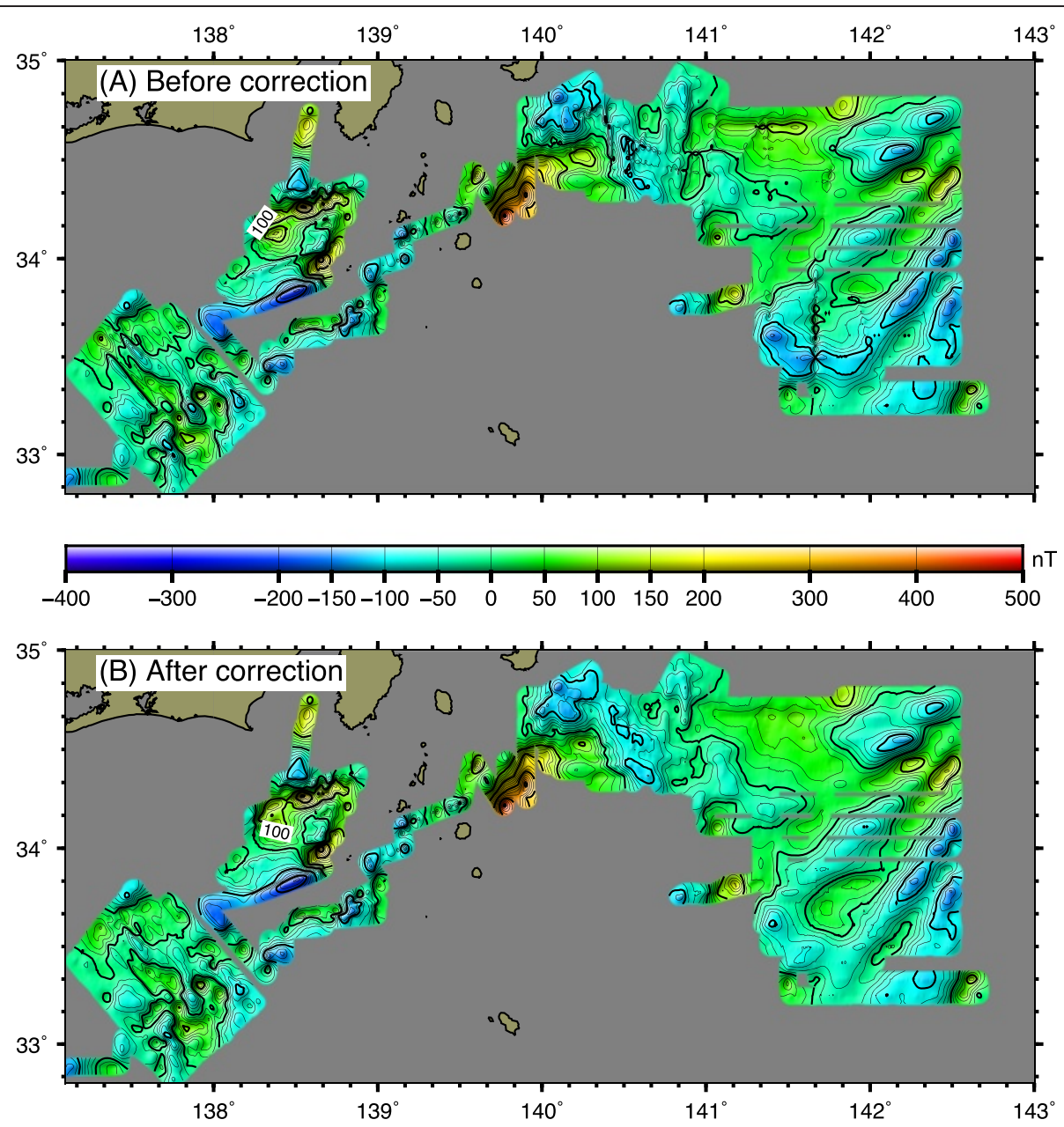

Figure 8 Magnetic anomaly maps from the Kaiko project before and after leveling correction. False anomalies along some of the track lines in the map before correction (A) disappear after leveling correction using a filtering width of $6 \mathrm{~h}$ and a weight distance of $0.5 \mathrm{~km}$ (B). Some improvements in anomaly patterns are also recognized in the box at the southwest end. Contours are at $20 \mathrm{nT}$ intervals; thicker contours are at $100 \mathrm{nT}$ intervals. 
from the GEODAS. The uncorrected magnetic anomaly map (Figure 8A) showed major features including $\mathrm{M}$-series anomalies associated with the subducting Pacific plate in the eastern part (Nakanishi et al. 1989). However, false anomalies along track lines were also recognized in this map, although they were not as conspicuous as those shown in the previous example.

The above leveling method was then applied to this data set by using a filtering width of $6 \mathrm{~h}$ and a weight distance of $0.5 \mathrm{~km}$. Most of the anomalies along the track lines disappeared after using this leveling correction (Figure $8 \mathrm{~B}$ ), and the spatial variations of anomaly values generally became smoother. It is of particular note that the anomaly pattern of the box at the southwest end also improved using this leveling correction. Its shape was initially extended slightly along a NW-to-SE direction (i.e., the direction of the track line), but after leveling correction, the shape was seen to be more rounded and isotropic. It is also noteworthy that no adjustment of the data in this box can be made using ordinary line leveling methods because there are no crossovers in this area.

There was a close correlation between the corrections obtained using this method and the 1-min total intensity values at the Kakioka Observatory (KAK) north of the survey area (Figure 9, location of KAK is shown in Figure 7). Very similar variations were observed particularly during the time periods when the leveling corrections were calculated using Equation 11a (red curve). Although there were no crossovers at the beginning part with a time
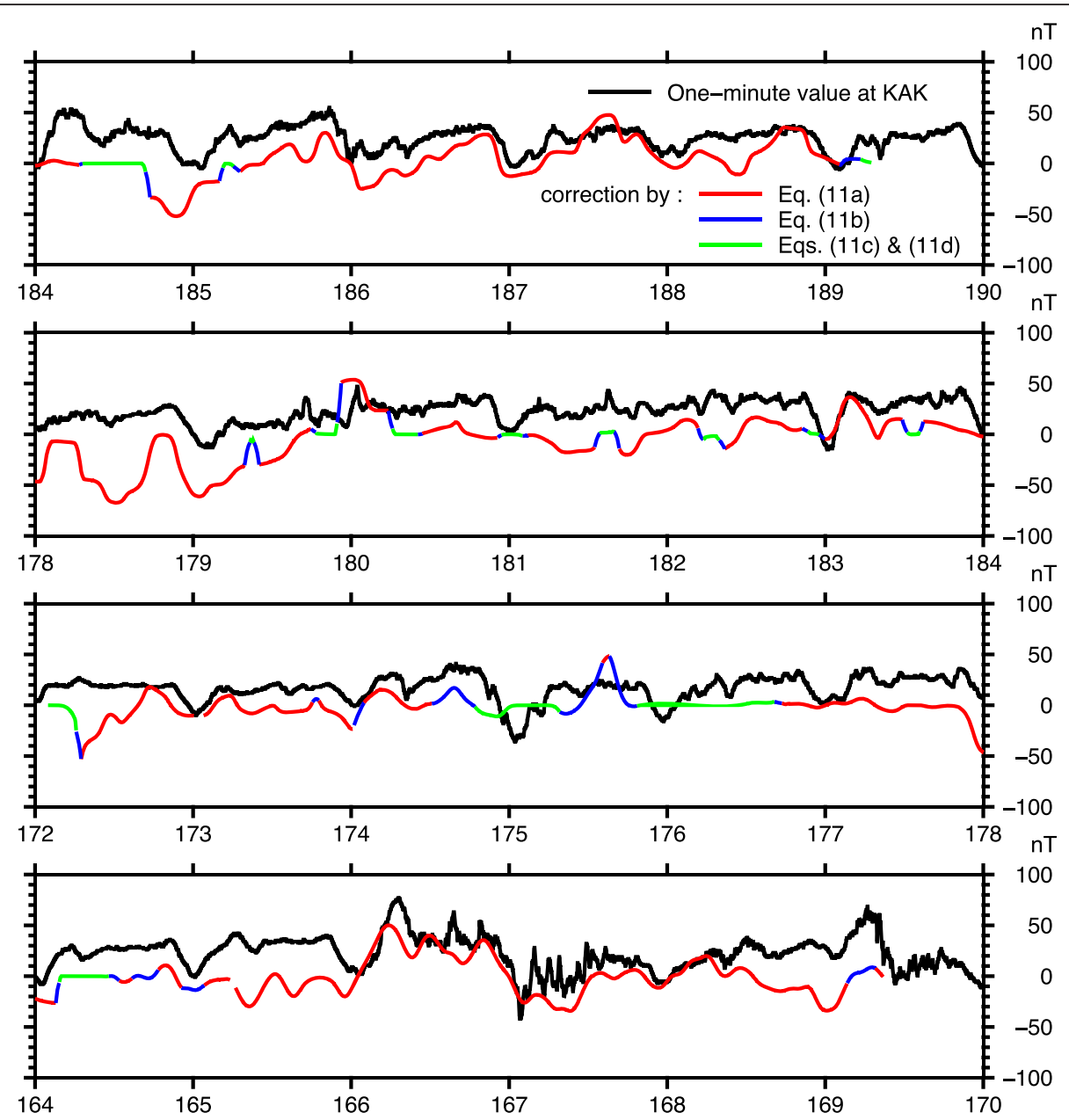

Days since the beginning of year 1984

Figure 9 Comparison of the total magnetic intensity 1-min values at the Kakioka Observatory (KAK) and leveling corrections. An approximate value of $46,000 \mathrm{nT}$ is subtracted from the 1-min values, and the subtracted values (black) are compared with leveling corrections along the track lines of the 84002111 and 84002112 cruise/legs of the R/V Jean Charcot. Good correlation was obtained particularly between the 1-min values and the corrections calculated by Equation 11 a (red curve). 
of $t<170$ days (which corresponds to the abovementioned box in the southwest end), most of the leveling corrections in this part can be also calculated using Equation 11a because there were enough data, which contribute to the corrections, in the neighboring track lines parallel to each other with a spacing of about 1.5 nautical miles. Corrections obtained by Equations $11 \mathrm{~b}$ to $11 \mathrm{~d}$ are less reliable, particularly during a transit period from one survey area to another, like that from the end of day 174 to the end of day 176, although the amplitudes of corrections were suppressed by the equations. The standard deviation of 139 CODs in this survey was reduced to one third of that of the original data (from 21.5 to $7.0 \mathrm{nT}$ ) using the leveling corrections.

\section{Example 3: survey of the Minami-Hiyoshi Seamount}

The Minami-Hiyoshi Seamount is an active submarine volcano with a summit at a depth of $99 \mathrm{~m}$ (Figure 10). The seamount produced underwater volcanic eruptions in 1975 and 1976. Geophysical surveys conducted to reveal its subsurface structure were carried out by the Japan Hydrographic and Oceanographic Department in 2001 (Onodera et al. 2002), and detailed digital magnetic data at a sampling interval of $20 \mathrm{~s}$ are now available from the GEODAS.

False anomalies were not clearly recognized around the summit area of the uncorrected magnetic anomaly map (Figure 11A), as these were hidden by largeamplitude anomalies associated with the volcano (with a maximum $>1,000 \mathrm{nT}$ and a minimum $<-1,000 \mathrm{nT}$ ).

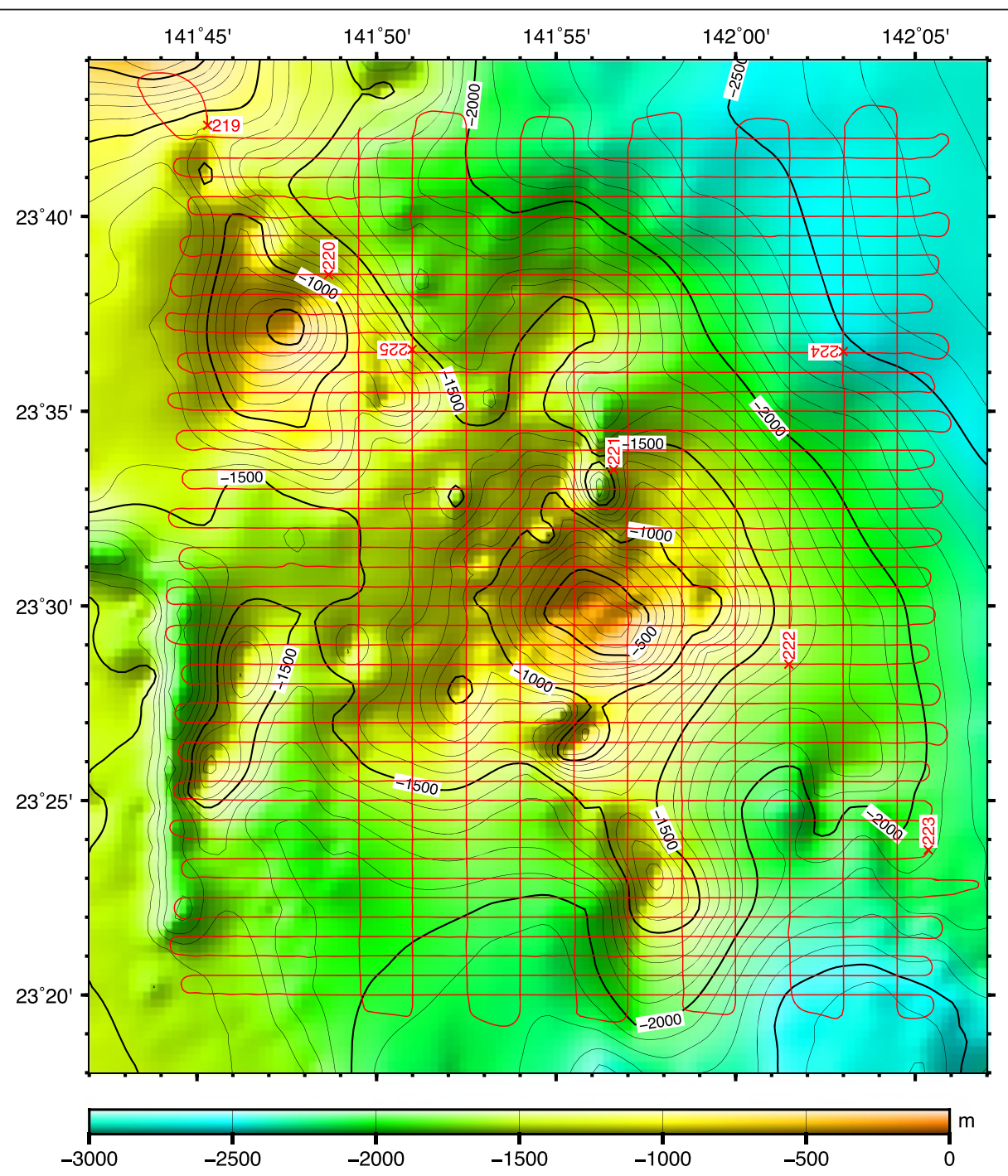

Figure 10 Track lines of magnetic survey cruise HS010808 over the Higashi-Hiyoshi Seamount. The detailed survey with spacings of 0.5 nautical miles for the E-to-W lines and about 1.5 nautical miles for the N-to-S lines was carried out in 2001 by the Japan Hydrographic and Oceanographic Department. Each red numeral shows the first location of the corresponding day of year. The bathymetric map was made using 30-s gridded data from Becker et al. (2009). 


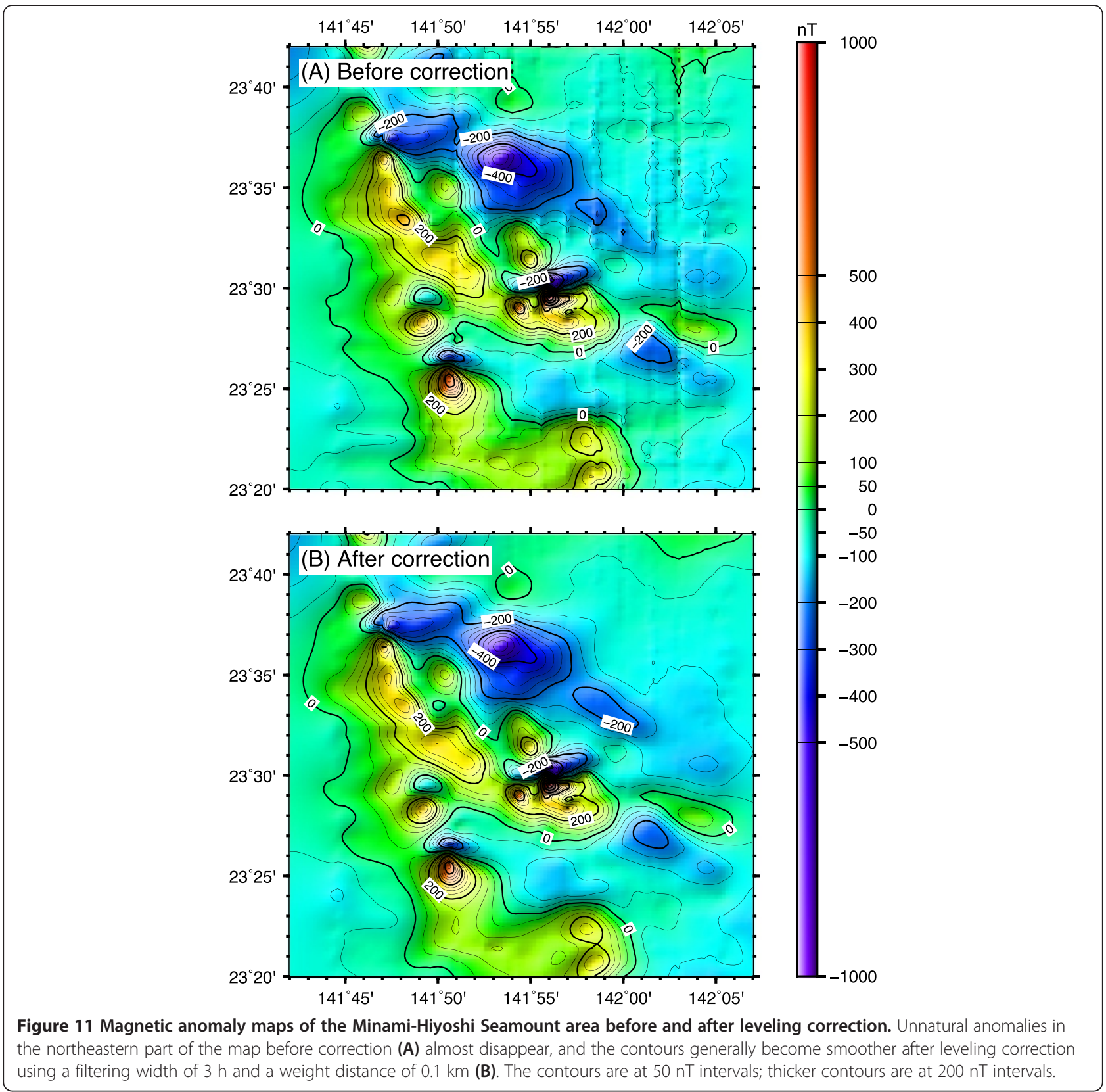

Unnatural false anomalies were visible, however, and these were particularly apparent northeast of the seamount. Notably, these false anomalies were seen to almost disappear after leveling correction with a weight distance of $0.1 \mathrm{~km}$ and a filtering width of $3 \mathrm{~h}$ (Figure 11B). The standard deviation of 493 CODs was reduced to one fifth of that of the original data (from 25.6 to $5.4 \mathrm{nT}$ ) in this case.

\section{Discussion}

\section{Weight distance and filtering width}

The proposed leveling method has two key parameters: weight distance $d_{0}$ and filtering width $2 t_{0}$. In order to show the accuracy improvement for various weight distances and filtering widths, the results on the standard deviations of CODs are summarized in Table 1.

In a detailed survey, a better result can be expected when selecting a smaller filtering width. This was confirmed by histograms of CODs for Example 3 (survey of the MinamiHiyoshi Seamount) assuming no correction and three different filtering widths $2 t_{0}$ (and the same weight distance $d_{0}$ of $0.1 \mathrm{~km}$ ) (Figure 12A). The standard deviation of CODs decreased with a decrease in the filtering width of $2 t_{0}$ (Table 1). Figure 12B shows a comparison of the corrections made using the three filtering widths and 1-min values recorded at the Chichijima Observatory $(\mathrm{CBI})$, 
Table 1 Standard deviations (SDs) of crossover differences (CODs)

\begin{tabular}{llll}
\hline & Filtering Width & Weight Distance & SD \\
\hline Example 1 - 1021 CODs & No correction & No & $74.6 \mathrm{nT}$ \\
& $3 \mathrm{~h}$ & $2.0 \mathrm{~km}$ & $28.0 \mathrm{nT}$ \\
Example 2 - 139 CODs & No correction & No & $21.5 \mathrm{nT}$ \\
& $6 \mathrm{~h}$ & $0.5 \mathrm{~km}$ & $7.0 \mathrm{nT}$ \\
Example 3 - 493 CODs & No correction & No & $25.6 \mathrm{nT}$ \\
& $3 \mathrm{~h}$ & $0.5 \mathrm{~km}$ & $17.1 \mathrm{nT}$ \\
& $3 \mathrm{~h}$ & $0.2 \mathrm{~km}$ & $7.1 \mathrm{nT}$ \\
& $12 \mathrm{~h}$ & $0.1 \mathrm{~km}$ & $13.3 \mathrm{nT}$ \\
& $6 \mathrm{~h}$ & $0.1 \mathrm{~km}$ & $8.3 \mathrm{nT}$ \\
& $3 \mathrm{~h}$ & $0.1 \mathrm{~km}$ & $5.4 \mathrm{nT}$ \\
\hline
\end{tabular}

which is located north of the survey area $\left(27.096^{\circ} \mathrm{N}\right.$, $\left.142.185^{\circ} \mathrm{E}\right)$. Shorter period components appeared when smaller filtering widths were selected. Corrections for a filtering width of $6 \mathrm{~h}$ were reasonably well correlated with the variations seen at CBI, and most of the corrections for $3 \mathrm{~h}$ also corresponded to the observatory data. In this survey, the correction of each measurement could be accurately determined thanks to numerous neighboring data, but the filtering width must always be chosen in accordance with the precision of the survey. Although a filtering width of $3 \mathrm{~h}$ was adopted to simulate short period variation in Example 1, a width of $6 \mathrm{~h}$ was selected in Example 2 , which delivered a reasonable result.

In a detailed survey, it is also expected that, when the weight distance is smaller, the CODs also become smaller, because data with large weights are limited in a smaller circle around the measured point. This was also confirmed by histograms of CODs for Example 3 assuming no correction and three different weight distances $d_{0}$ (using the same filtering width of $3 \mathrm{~h}$ ) (Figure 12C). The standard deviation of CODs decreased with decreasing values of $d_{0}$ (Table 1 ).

However, in order to reduce CODs, a shorter sampling interval is also required in addition to a smaller weight distance, so that at least one of the neighboring data points exists inside the circle of the small weight distance $d_{0}$. For a speed of 10 knots, sampling intervals of $5 \mathrm{~min}, 1 \mathrm{~min}$, and $20 \mathrm{~s}$ correspond to spatial intervals of about 1,540, 310 and $100 \mathrm{~m}$, respectively. In this study, weight distances of 2,000,500, and $100 \mathrm{~m}$ were adopted in Example 1 (sampling interval of $5 \mathrm{~min}$ and actual average spatial interval of 2,170 m), Example 2 (1 min and $298 \mathrm{~m}$ ), and Example 3 (20 s and $82 \mathrm{~m}$ ), respectively.

These examples indicate that this method improved the accuracy of magnetic anomalies, whereby CODs were reduced by one third to one fifth when using a good weight distance and a good filtering width. The results also suggest that if an area where a detailed survey is conducted does not have a base station or a close observatory, this new leveling method can deliver reliable temporal variation.

\section{Weight function and distance limit}

Generally speaking, a function, which decreases approximately as a negative $n$-th power of the distance $d$, can be considered as the weight function. However, $n$ should be greater than 2 because contributions of remote data in the weight function are too big when $n=2$; this is understandable from the fact that the corresponding integral for the homogeneous data distribution, $2 \pi \int_{0}^{D} r d r /\left[1+\left(r / d_{0}\right)^{2}\right]$, increases to infinity with an increase of $D$.

The author assumed $n=4$. As just discussed above, this is a function that decreases rapidly enough to minimize the crossovers. It is probably unnecessary to adopt a function that decreases more rapidly with $n>4$. Owing to the application of low-pass filtering, reasonable corrections to data can be obtained, including to those outside of the adopted weight distance from the nearest crossovers, although many of the weights for their own data in the filtering calculation are small. This is justified by the high correlations of the obtained corrections with the variations of observatory data shown in the three examples. The corrections in the southwestern box in Example 2 also show that this weight function with appropriate low-pass filtering can give good results even when there are no crossovers and only closely separated track lines in the survey area. One problem in the method using this function is that this can be applied successfully only to detailed surveys with close track lines and/or many crossovers. As shown in Example 2, no accurate correction can be obtained when there are not enough neighboring data. Although the author has not tried to apply a weight function with $n=3$ yet, it might be another possibility particularly suitable for more regional surveys with fewer crossovers and with wider track line spacings.

A value of $15 \mathrm{~km}$ was adopted as the distance limit $d_{1}$ in this paper. Maus et al. (2007) obtained a value of $15 \mathrm{~km}$ as the correlation length for gridded magnetic data of the former Soviet Union, Australia, and North America. This means that correlation between two magnetic data points with horizontal distances of $>15 \mathrm{~km}$ decreases rapidly. Maus et al. (2009) further obtained anisotropic values of 7 to $28 \mathrm{~km}$ for the correlation length in oceanic areas. In order to use only highly correlated data in the weighted average, the author simply adopted a value of $15 \mathrm{~km}$, although it may be more appropriate to take such anisotropy into consideration. Anyway, the adopted weight function decreased rapidly; it became 0.01 when $d=3 d_{0}$ 


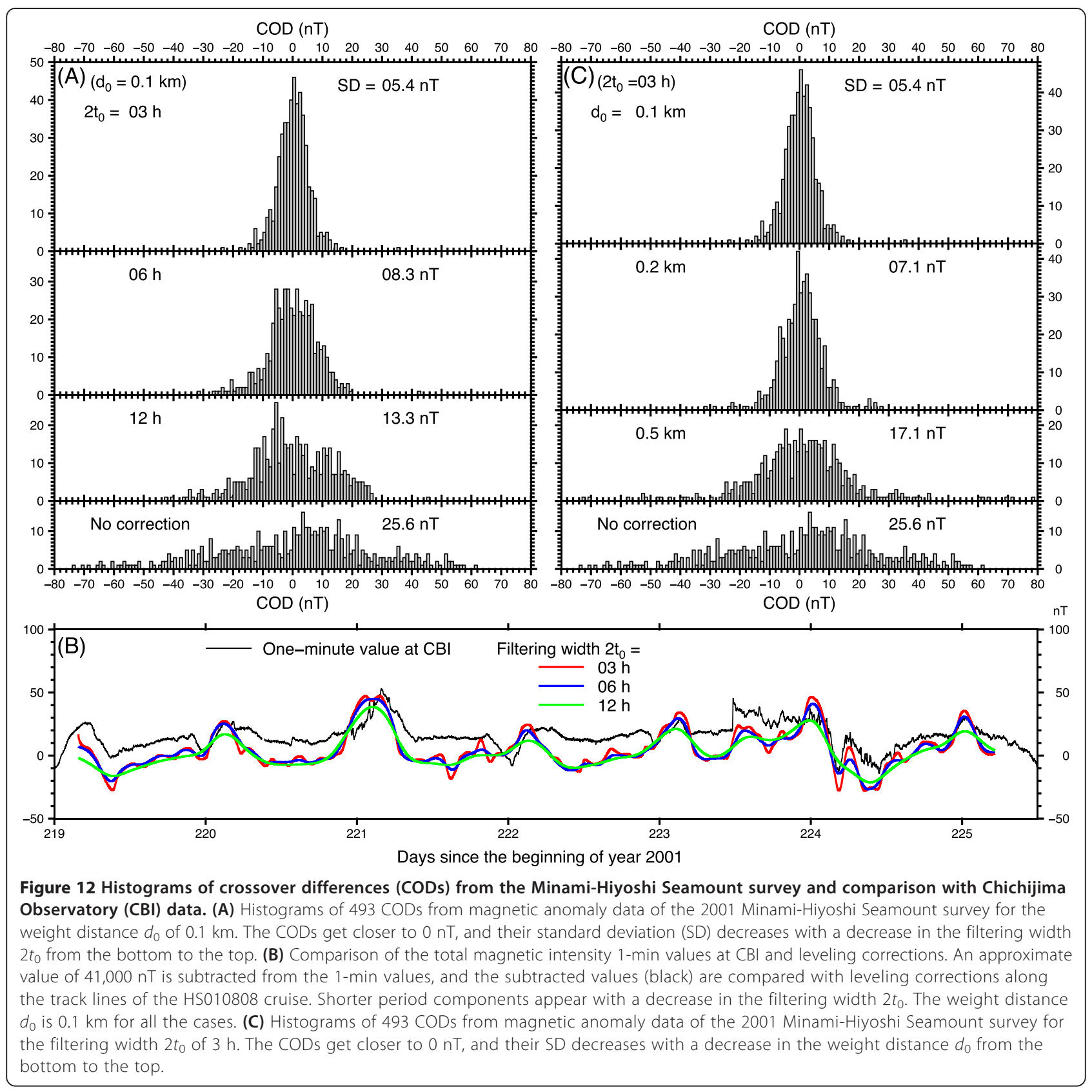

(Figure 2). The corresponding integral for the homogeneous data distribution of $2 \pi \int_{0}^{d} r d r /\left[1+\left(r / d_{0}\right)^{2}\right]^{2}$ for $d=3 d_{0}$ became 0.9 of the integral for the whole data $2 \pi \int_{0}^{\infty} r d r /\left[1+\left(r / d_{0}\right)^{2}\right]^{2}$, i.e., $90 \%$ of the sum of weights of the whole data was included inside this distance. This is just $d_{1}$ for $d_{0}=5 \mathrm{~km}$. A smaller value of $d_{1}$ can be selected for a smaller value of $d_{0}$, unless there are no crossovers in the survey area like the southwest box in Example 2.

\section{Conclusions}

The new leveling method presented in this study is able to improve the accuracy of anomaly data collected by detailed magnetic surveys. The above examples show that the CODs were reduced by between one third and one fifth by choosing the appropriate values of two parameters: the weight distance and the filtering width. This study also suggests the possibility of being able to estimate temporal variation during a survey without using a base station. In order to simplify the explanation, the above examples were from magnetic surveys that had a short duration of less than a few months. However, this 
method can be extended easily to cases of longer duration, and if applied to surveys of the same areas over a number of years, the results will include the effect of secular variation in the main field.

\section{Abbreviations}

AUV: autonomous underwater vehicle; CBI: Chichijima Observatory; CM4: Comprehensive Model 4; COD: crossover difference; CWE: Cape Wellen Observatory; GEODAS: Geophysical Data System (of the US National Geophysical Data Center); GMT: Generic Mapping Tools; GPS: Global Positioning System; IFREMER: French Research Institute for the Exploitation of the Sea; IGRF: International Geomagnetic Reference Field; KAK: Kakioka Observatory; NOAA: National Oceanic and Atmospheric Administration; RMS: root mean square; ROV: remotely operated vehicle; SD: standard deviation.

\section{Competing interests}

The author declares that he has no competing interests.

\section{Acknowledgements}

The author would like to thank Hirokuni Oda for his constructive comments. Thanks are also given to two anonymous reviewers for various suggestions and comments that helped to improve the manuscript. Marine magnetic data were obtained through the US National Geophysical Data Center. In addition, the author would like to thank NOAA, the French Research Institute for the Exploitation of the Sea (IFREMER), and the Japan Hydrographic and Oceanographic Department for making their data available for this study. One-minute data at the Kakioka and Chichijima Observatories were obtained from the Kakioka Geomagnetic Observatory, and hourly values at the Cape Wellen Observatory were made available through the World Center for Geomagnetism in Edinburgh. All figures were created using the Generic Mapping Tools (GMT) software (Wessel et al. 2013).

Received: 3 September 2014 Accepted: 6 January 2015

Published online: 27 January 2015

\section{References}

Becker JJ, Sandwell DT, Smith WH, Braud J, Binder B, Depner J, Fabre D, Factor J, Ingalls S, Kim S-H, Ladner R, Marks K, Nelson S, Pharaoh A, Trimmer R, Von Rosenberg J, Wallace G, Weatherall P (2009) Global bathymetry and elevation data at 30 arc seconds resolution: SRTM30_plus. Mar Geodesy 32:355-371

Hamoudi M, Quesnel Y, Dyment J, Lesur V (2011) Aeromagnetics and marine measurements. In: Mandea M, Korte M (eds) Geomagnetic observations and models (IAGA Special Sopron Book Series), vol 5. Springer, Heidelberg, pp 57-103

Honsho C, Ura T, Kim K (2013) Deep-sea magnetic vector anomalies over the Hakurei hydrothermal field and the Bayonnaise knoll caldera, Izu-Ogasawara arc, Japan. J Geophys Res: Solid Earth 118:5147-5164. doi:10.1002/jgrb.50382

Hsu S (1995) XCORR: a cross-over technique to adjust track data. Comput Geosci 21:259-271

International Association of Geomagnetism and Aeronomy, Working Group V-MOD (2010) International Geomagnetic Reference Field: the eleventh generation. Geophys J Int 183:1216-1230. doi:10.1111/j.1365-246X.2010.04804.x

Isezaki N (1986) A new shipboard three-component magnetometer. Geophysics 51:1992-1998

Le Pichon X, Kobayashi K, Cadet J-P, liyama T, Nakamura K, Pautot G, Renard V, the Kaiko Scientific Crew (1987) Project Kaiko - introduction. Earth Planet Sci Lett 83:183-185

Maus S, Sazonova T, Hemant K, Fairhead JD, Ravat D (2007) National Geophysical Data Center candidate for the World Digital Magnetic Anomaly Map. Geochem Geophys Geosys 8, Q06017. doi:10.1029/2007GC001643

Maus S, Barckhausen U, Berkenbosch H, Bournas N, Brozena J, Childers V, Dostaler F, Fairhead JD, Finn C, von Frese RRB, Gaina C, Golynsky S, Kucks R, Lühr H, Milligan P, Mogren S, Müller RD, Olesen O, Pilkington M, Saltus R, Schreckenberger B, Thébault E, Tontini FC (2009) EMAG2: a 2-arc min resolution Earth Magnetic Anomaly Grid compiled from satellite, airborne, and marine magnetic measurements. Geochem Geophys Geosys 10, Q08005. doi:10.1029/2009GC002471

Mittal PK (1984) Algorithm for error adjustment of potential field data along a survey network. Geophysics 49:467-469
Nakanishi M, Tamaki K, Kobayashi K (1989) Mesozoic magnetic anomaly lineations and seafloor spreading history of the northwestern Pacific. J Geophys Res 94:15437-15462

Olsen N, Friis-Christensen E, Floberghagen R, Alken P, Beggan CD, Chulliat A, Doornbos E, da Encarnaçao JT, Hamilton B, Hulot G, van den IJssel J, Kuvshinov A, Lesur V, Lühr H, Macmillan S, Maus S, Noja M, Olsen PEH, Park J, Plank G, Püthe C, Rauberg J, Ritter P, Rother M, Sabaka TJ, Schachtschneider R, Sirol O, Stolle C, Thébault E, Thomson AWP (2013) The Swarm Satellite Constellation Application and Research Facility (SCARF) and Swarm data products. Earth Planets Space 65:1189-1200

Onodera K, Nishizawa A, Kato T, Seo N, Kubota R (2002) Geomagnetic and gravity anomalies and seismic velocity structures of Fukutoku-Oka-no-Ba and Minami-Hiyoshi seamounts. Gekkan Chikyu Gogai 39:165-171 (in Japanese)

Quesnel Y, Catalán M, Ishihara T (2009) A new global marine anomaly data set. J Geophys Res 114, B04106. doi:10.1029/2008JB006144

Sabaka TJ, Olsen N, Langel RA (2002) A comprehensive model of the quiet-time, near-Earth magnetic field: phase 3. Geophys J Int 151:32-68

Sabaka TJ, Olsen N, Purucker ME (2004) Extending comprehensive models of the Earth's magnetic field with Ørsted and CHAMP data. Geophys J Int 159:521-547

Sanders EL, Mrazek CP (1982) Regression technique to remove temporal variation from geomagnetic survey data. Geophysics 47:1437-1443

Szitkar F, Dyment J, Fouquet Y, Honsho C, Horen H (2014) The magnetic signature of ultramafic-hosted hydrothermal sites. Geology 42:715-718

Wessel P (2010) Tools for analyzing intersecting tracks: the x2sys package. Comput Geosci 36:348-354

Wessel P, Smith WHF, Scharroo R, Luis JF, Wobbe F (2013) Generic Mapping Tools: improved version released. EOS Trans AGU 94:409-410

Yarger HL, Robertson RR, Wentland RL (1978) Diurnal drift removal from aeromagnetic data using least squares. Geophysics 46:1148-1156

\section{Submit your manuscript to a SpringerOpen ${ }^{\circ}$ journal and benefit from:}

- Convenient online submission

- Rigorous peer review

- Immediate publication on acceptance

- Open access: articles freely available online

- High visibility within the field

- Retaining the copyright to your article

Submit your next manuscript at $>$ springeropen.com 